\title{
DESAIN SIGNAGE SYSTEM SEBAGAI MEDIA INFORMASI KAWASAN SIMPANG LIMA SEMARANG BERBASIS KOMPUTER GRAFIS
}

\author{
Ahmad Akrom ${ }^{1}$, Toto Haryadi² \\ 1,2 Program Studi Desain Komunikasi Visual, Fakultas Ilmu Komputer, Universitas Dian Nuswantoro \\ 1ahmad.akrom@dsn.dinus.ac.id, ²toto.haryadi@dsn.dinus.ac.id
}

\begin{abstract}
Abstrak
Kota Semarang merupakan ibu kota Provinsi Jawa Tengah yang berlokasi di Pantura (pesisir pantai utara Jawa. Simpang Lima menjadi kawasan strategis di Semarang dan layak dikunjungi karena menjadi pusat kegiatan ibadah, rekreasi, belanja, serta aktivitas positif lainnya. Namun, potensi yang dimiliki Simpang Lima belum bisa dieksplorasi secara maksimal karena kurang tersedianya media informasi untuk pengunjung, khususnya dalam bentuk signage system. Padahal, signage system memiliki fungsi penting dalam memberi informasi tentang nama dan lokasi suatu tempat. Hal tersebut mendorong penulis melakukan penelitian desain signage system dengan metode kualitatif. Data penelitian diperoleh melalui observasi, wawancara, kuesioner, dan studi pustaka. Desain signage system dikembangkan menggunakan signage pyramid method yang terdiri dari tiga tahapan: information content system, graphic system, serta hardware system. Hasil penelitian ini yaitu desain signage system beberapa tempat penting di Simpang Lima beserta mockup pemasangan di lokasi tersebut. Penelitian ini bisa dikembangkan lebih lanjut dengan mengadaptasi teknologi augmented reality yang mampu menyajikan signage system secara virtual dan bisa diakses melalui perangkat smartphone.
\end{abstract}

Kata Kunci: media informasi, simpang lima, signage system, placemaking

\begin{abstract}
Semarang is the capital city of Central Java located on Pantura (the northern coast of Jawa). Simpang Lima becomes a strategic area in Semarang well worth a visit by citizens and tourism for being the center of activities such as worship, recreation, shopping, and also other positive activities event. However, the potential of Simpang Lima cannot fully be explored due to a lack of information for visitors, especially in a signage system form. Nevertheless, a signage system's primary function was providing information about the name and location of places. This case has pushed the authors to research signage system design by using the qualitative method. Research data obtained by observation, interview, questionnaire, and literature study. Signage system design developed using the Signage Pyramid Method that consists of three steps: information content system, graphic system, and hardware system. The result of this research is the signage system design of some primary places in Simpang Lima and a mock-up of installation on that place. This research can be developed further by adapting augmented reality technology that can present the signage system virtually so it can be accessed by using a smartphone.
\end{abstract}

Keywords: information media, simpang lima, signage system, placemaking 


\section{PENDAHULUAN}

Kota Semarang merupakan ibukota Provinsi Jawa Tengah yang berlokasi di pesisir pantai utara Jawa (Pantura). Status Semarang sebagai kota metropolitan yang layak bersanding dengan kota-kota besar seperti Jakarta, Bandung, dan Surabaya mendorong pemerintah kota untuk terus berprestasi. Hal ini dimulai dari penerimaan penghargaan gold pada Juli 2019 sebagai keberhasilan membangun infrastruktur berdampak positif dalam mendongkrak pertumbuhan ekonomi (Nasrulhak, 2019), yang berlanjut pada bulan November dengan menerima sembilan kategori penghargaan Kota Menuju Cerdas Goesmart 2019 (Maarif, 2019). Pada awal 2020 Semarang memperoleh predikat kota wisata terbersih di ASEAN sebagai upaya mendongkrak pariwisata (Aditya, 2020), berikutnya di tengah pandemi bulan Juni 2020 Semarang kembali menerima penghargaan Inovasi Tatanan New Normal 5 sektor: wisata, hotel, transportasi umum, pasar rakyat, serta pasar modern (Kurniawan, 2020).

Dari segi infrastruktur, kota Semarang memiliki kawasan-kawasan strategis yang menjadi daya tarik, salah satunya yaitu Simpang Lima. Kawasan ini strategis, ramai, dan menjadi pusat perhatian karena terdapat multi aktivitas berbagai bidang meliputi: perekonomian, perkantoran, pendidikan, jasa, Ruang Terbuka Hijau (RTH), serta sosial budaya (Santoso et al., 2020:35). Bersama dengan Pandanaran, Pemuda, dan Gajah mada, Simpang Lima juga menjadi kawasan bisnis terpadu yang mengalami perkembangan pesat dan efisien selama 10 tahun terakhir (Widyaningrum et al., 2017:103).

Potensi Simpang Lima yang sangat besar tidak hanya menjadi perhatian pemerintah kota dan investor untuk meningkatkan value dalam konteks komersial. Para akademisi dari dunia pendidikan juga menjadikan Simpang Lima sebagai objek penelitian berbagai bidang meliputi: tata wilayah, aktivitas manusia, transportasi, lingkungan, serta advertising. Khususnya advertising, Simpang Lima menjadi objek penelitian yang dikaji potensinya sebagai kawasan ideal dalam pemasangan iklan beserta konsep penyajiannya yang sesuai dengan tata wilayah (Prastomo \& Widjaja, 2019), serta adaptasi teknik retorika iklan yang digunakan pada beberapa media billboard di sisi Simpang Lima bagian barat dan timur sebagai cara untuk untuk menarik atensi audiens (Haryadi dan Saputro, 2018:104).

Kedua penelitian advertising terkait Simpang Lima di atas merupakan bagian dari penggalian potensi signage system. Signage system sendiri merupakan salah satu komponen Environmental Graphic Design (EGD). EGD merupakan komunikasi berbasis grafis berisi informasi mengenai lingkungan tertentu yang terdiri dari tiga komponen utama meliputi: signage (dan wayfinding), placemaking, serta interpretation (Calori \& Vanden-Eynden, 2015). EGD memiliki kepentingan utama sebagai sarana komunikasi dengan berorientasi pada aspek fungsi dan mempertimbangkan human centered design, user interface, serta user experience (Hananto \& et al., 2019:181). Berdasarkan observasi penulis, pemanfaatan EGD di kawasan Simpang Lima sejauh ini belum maksimal karena didominasi oleh reklame-reklame saja. Adapun ketersedian media informasi dalam bentuk signage atau placemaking belum mendapat prioritas karena ada yang 
mengalami kerusakan akibat kurang perawatan, ada yang letaknya tersembunyi terhalang pohon dan bagian dari bangunan sekitarnya, desain signage system yang tidak konsisten, serta ada juga lokasi penting yang belum memiliki signage system sama sekali. Hal ini juga sesuai dengan hasil studi pustaka penulis yang belum menemukan penelitian atau usulan tentang perancangan signage system di kawasan Simpang Lima Semarang dari akademisi.

Permasalahan tersebut mendorong penulis melakukan penelitian berupa desain signage system Kawasan Simpang Lima Semarang, yang didasarkan pada pertimbangan bahwa ketiga komponen EGD (signage, placemaking, interpretation) memiliki fungsi penting yakni sebagai media informasi yang menuntun audiens tentang suatu tempat, memberikan identitas terhadap sebuah lokasi, serta memaparkan informasi sebuah tempat dengan jelas dan mudah dimengerti. Hal ini juga didasarkan pada Peraturan Menteri Pekerjaan Umum No. 20/PRT/M2010 pasal 3 ayat b tentang salah satu pemanfaatan ruang manfaat jalan yaitu sebagai tempat menyajikan media informasi di dalam ruang milik jalan (KPUPR), 2010). Adanya signage system sangat membantu masyarakat Semarang maupun wisatawan yang sedang berkunjung ke Simpang Lima sehingga bisa mendapatkan informasi serta bisa mengeksplorasi tempat-tempat strategis yang bisa dikunjungi dalam berbagai keperluan tidak hanya refreshing, tetapi juga bisnis dan pekerjaan.

Tujuan penelitian ini yaitu menyajikan desain signage system berbasis komputer grafis yang komunikatif dan estetis agar media informasi bisa dihadirkan secara konsisten dan mencitrakan Simpang Lima sebagai kawasan modern dan kekinian, yang menjadi ciri khas Semarang kota metropolitan. Penelitian ini juga dimaksudkan untuk memperkuat city branding Semarang sekaligus menampilkan wajah lain kota Semarang yang selama ini lebih dikenal sebagai kota bersejarah seperti kawasan Tugu Muda saja sebagaimana dibahas dalam penelitian terdahulu tentang perancangan sign system objek pariwisata Lawang Sewu di kota Semarang yang menghasilkan desain EGD dengan tiga komponen utamanya (Amrullah \& Tohir, 2017:828).

\section{METODE PENELITIAN}

Penelitian desain signage system kawasan Simpang Lima Semarang dilakukan dengan pendekatan kualitatif, yaitu menafsirkan fenomena yang terjadi dengan menempatkan peneliti sebagai instrumen kunci dalam meneliti objek yang alamiah serta hasil penelitian lebih menekankan pada makna (Anggito \& Setiawan, 2018:8). Objek dalam penelitian ini yaitu kawasan Simpang Lima Semarang yang mencakup lapangan Pancasila, gedung - gedung pemerintahan provinsi Jawa Tengah, Taman Indonesia Kaya, serta bangunan lain yang masih dalam lingkup kawasan.

Data yang digunakan dalam penelitian ini yaitu data primer dan sekunder. Data primer diperoleh melalui observasi ke kawasan Simpang Lima Semarang untuk mengamati ketersediaan signage system dan beragam tempat strategis beserta ciri fisiknya serta lokasinya. Observasi ditunjang dengan pengamatan kawasan Simpang Lima melalui foto citra satelit yang disajikan google map. Wawancara juga dilakukan untuk menggali data 
primer dengan menjadikan pengunjung sebagai narasumber. Pengalaman pengunjung selama berada di kawasan Simpang Lima sangat membantu penulis dalam merumuskan signage system yang akan didesain nantinya. Data sekunder diperoleh melalui studi pustaka dari jurnal penelitian tentang signage system baik yang bersifat terapan (perancangan) maupun fundamental (kajian).

Desain signage system kawasan Simpang Lima Semarang dirancang menggunakan Signage Pyramid Method, yaitu metode perancangan informasi berbasis grafis yang ditampilkan dalam objek fisik. Metode ini terdiri dari tiga tahap yaitu: information content system, graphic system, serta hardware system. Information content system mendeskripsikan informasi tentang nama dan lokasi suatu tempat, graphic systems menjelaskan atribut teknis visualisasi signage system melalui penggunaan elemen desain, dan hardware system menjabarkan alat atau media untuk mewujudkan signage system (Hananto \& et al., 2019:182). Ketiga tahap tersebut melibatkan komputer grafis sebagai sarana eksekusi desain signage system yang juga mempertimbangkan kriteria dalam Peraturan Menteri Pekerjaan Umum No. 20/PRT/M2010 pasal 17 ayat 3 tentang bentuk huruf, simbol atau warna dalam media informasi tidak boleh sama atau menyerupai dengan huruf, simbol dan warna yang digunakan untuk rambu-rambu lalu lintas.

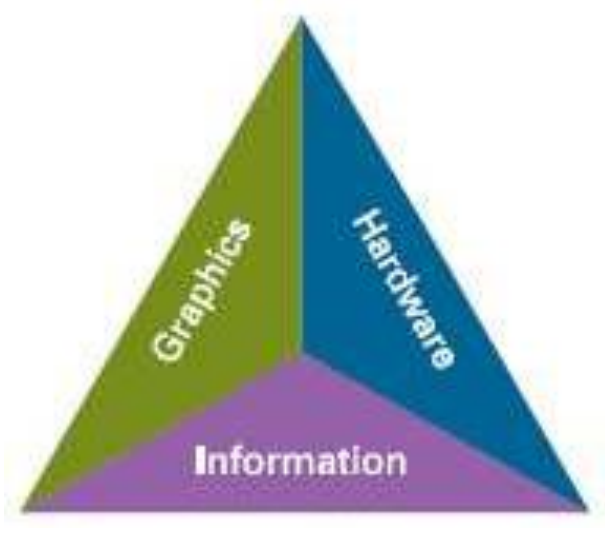

Gambar 1. Signage Pyramid method

[Sumber: Hananto \& et al., 2019:182]

Sebagaimana telah dijelaskan bahwa sign system berorientasi pada aspek fungsi dan mempertimbangkan human centered design, penyebaran angket juga dilakukan untuk mengumpulkan data dari 60 (enam puluh) responden untuk mendukung desain EGD agar maksimal dan sesuai dengan kebutuhan. Hasil data angket digunakan sebagai bahan pertimbangan teknis khususnya terkait tahap information content system dan graphic system dalam signage pyramid method, sehingga diharapkan hasil desain sign system nantinya mampu menjadi media informasi yang mudah dipahami oleh pengunjung dalam mengidentifikasi berbagai lokasi atau fasilitas di kawasan Simpang Lima kota Semarang.

Design thinking membantu proses analisis masalah untuk menemukan solusi, sehingga metode ini tidak fokus pada permasalahan yang ada, tetapi fokus pada penemuan solusi dari masalah yang ada (Radianto dkk, 2018:162-163). Awalnya metode ini lebih sering 
digunakan dalam bidang entrepreneurship (bisnis). Pada perkembangannya teori ini lebih luas penggunaannya, contohnya pada bidang desain dan pendidikan. Design thinking bersifat formal namun praktis, sebagai cara pencarian solusi yang kreatif dari masalah atau isu dengan tujuan untuk mendapatkan hasil yang lebih baik kedepannya. Design thinking juga mengaktualisasi ide dan konsep, yang terdiri dari lima tahapan, yaitu: Empathize, Define, Ideate, Prototype, dan Test (Ramdhan, 2016:36-37).

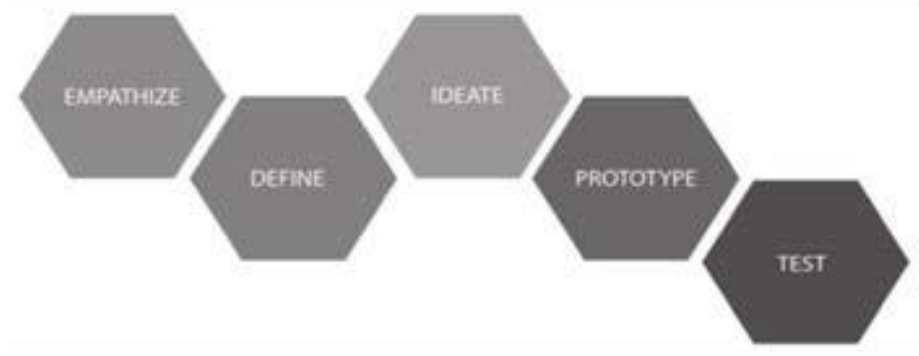

Gambar 2. Design Thinking

[Sumber: Ramdhan 2016:13]

\section{HASIL DAN PEMBAHASAN}

Desain signage system kawasan Simpang Lima Semarang berdasarkan dari hasil wawancara yang telah dilakukan kepada pengunjung dalam merespon pertanyaan terkait efektivitas signage system, pengunjung memberikan respon bahwa beberapa signage system belum berfungsi dengan baik karena letak atau posisinya yang terhalang pohon. Beberapa signage system dilanggar karena kebiasaan pengunjung lokal yang sengaja melakukan hal tersebut. Selain itu, desain signage system yang telah ada juga perlu diperbarui secara berkala dan dirawat dengan baik karena tingkat keterbacaan signage system berkurang akibat vandalisme. Potensi Simpang Lima yang strategis belum tergali secara keseluruhan, dikarenakan cukup banyaknya tempat atau lokasi yang bisa dikunjungi dan tersebar di sekitar lapangan Pancasila yang menjadi pusat (titik tengah) Simpang Lima. Melalui desain signage system, potensi tempat - tempat strategis di kawasan Simpang Lima bisa menarik minat wisatawan yang baru berkunjung ke Semarang.
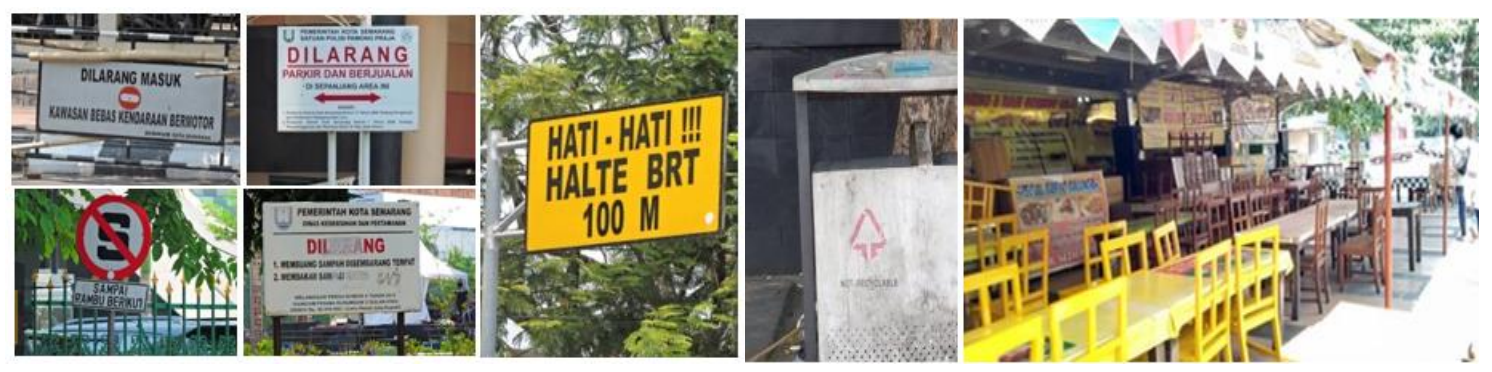

Gambar 3. Observasi beberapa signage system di kawasan Simpang Lima [Sumber: Project Signage System, penulis]

\subsection{Konsep Kreatif}

Pada penelitian ini, penulis mempertimbangkan hasil observasi, wawancara, serta pembagian angket sebagai landasan atau konsep kreatif desain signage system. Pertimbangan pertama yaitu karakteristik Simpang Lima yang modern dan kekinian, 
sehingga desain signage system yang digunakan bersifat universal untuk semua orang dari berbagai usia dan latar belakang. Universal di sini yaitu penggunaan gambar, ikon, atau simbol yang mudah dikenal dan tidak mengandung ornamen atau hiasan khusus, sebagaimana desain bangunan atau gedung di kawasan Simpang Lima yang bergaya modern. Berbeda dengan kawasan Kota Lama dan Tugu Muda Semarang yang memiliki ciri arsitektur khas Belanda sehingga memunculkan kesan klasik. Karakteristik modern ini diterjemahkan menjadi bahasa gambar signage system yang dibuat dengan pendekatan stilasi dan simplifikasi, yaitu penggayaan dan penyederhanaan suatu objek agar lebih mudah dipahami oleh audiens.

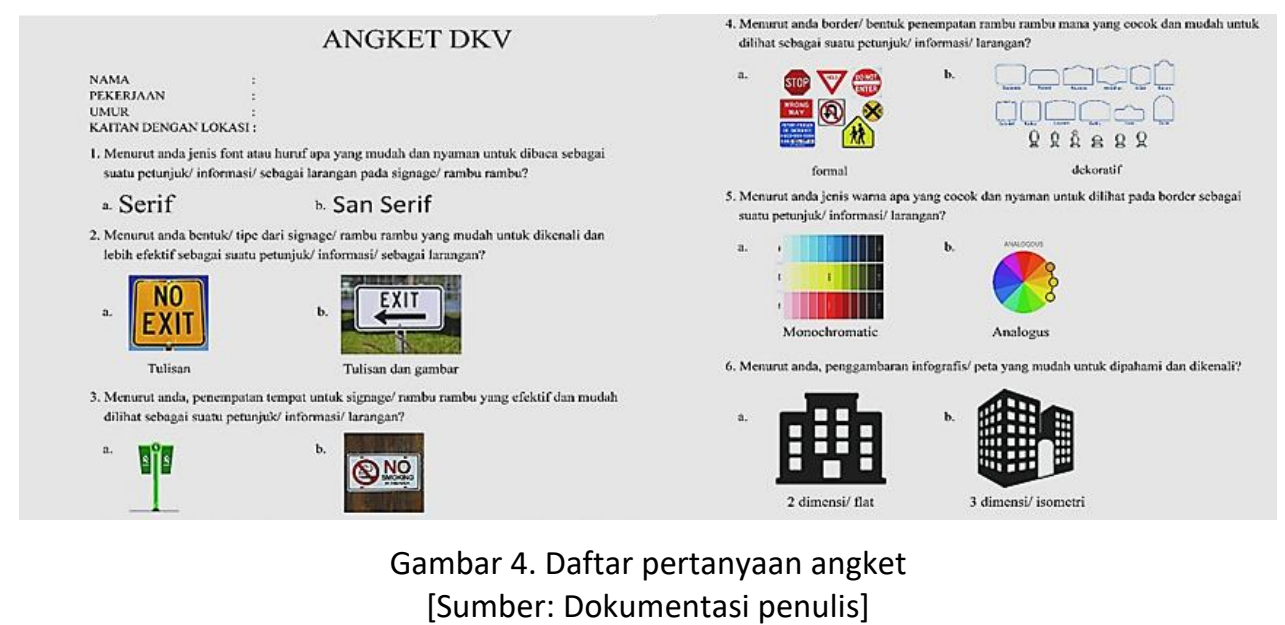

Pertanyaan angket sebagaimana tampak pada gambar 3 telah disebar kepada responden dari berbagai latar belakang, dan yang memiliki pengetahuan atau pengalaman terhadap kawasan Simpang Lima Semarang. Dari enam pertanyaan yang diberikan, hasilnya yaitu sebagai berikut:

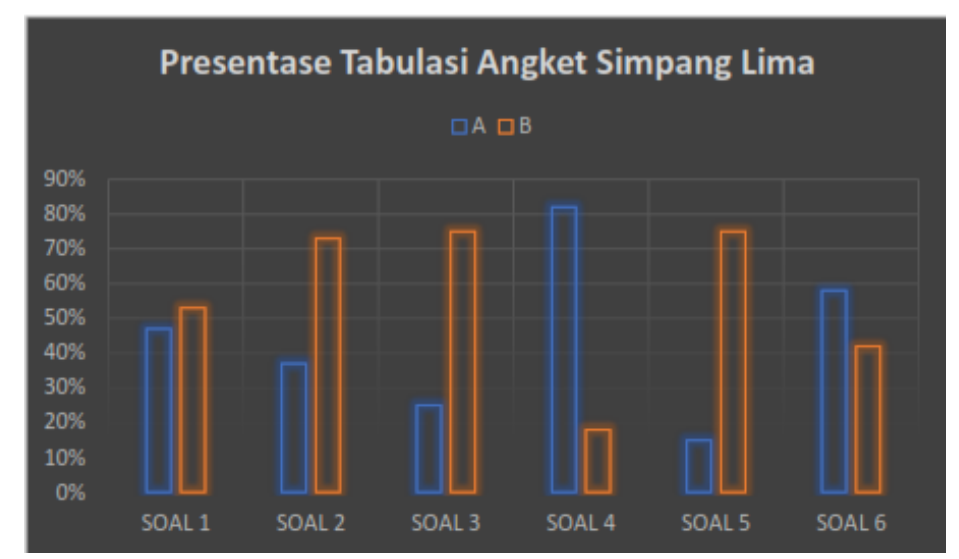

Gambar 5. Grafik hasil pengisian angket 60 responden [Sumber: Dokumentasi penulis]

Gambar 5 menunjukkan sebanyak 53\% responden memilih penggunaan tulisan San serif (huruf tegas tanpa kait) untuk informasi dalam signage system karena faktor keterbacaan. Terkait konten yang akan digunakan dalam signage system, sebanyak $73 \%$ responden memilih kombinasi gambar dan tulisan agar mudah dilihat dan dipahami. 
Konsep pemasangan signage system juga menjadi pertimbangan utama agar desain signage system menjadi media informasi yang jelas, dan sebanyak $75 \%$ responden memilih signage system dipasang di dinding daripada di tiang khususnya untuk tempat - tempat yang memiliki gedung atau bangunan. Bentuk frame signage system juga menjadi perhatian responden, yang mana sebanyak $81 \%$ lebih memilih desain frame standar sebagaimana banyak digunakan dalam rambu-rambu lalu lintas. Masih berkaitan dengan frame, sebanyak $75 \%$ responden memilih warna analogus (warna berdekatan) untuk diterapkan dalam desain border signage system. Poin terakhir tentang visualisasi signage system, 58\% responden lebih memilih gambar 2D flat tampak depan atau samping dibanding gambar perspektif yang tampak seperti 3D.

\subsection{Proses Kreatif Desain Signage System}

Penggunaan Signage Pyramid Method mempermudah proses visualisasi desain signage system mulai dari penentuan informasi apa saja yang akan disajikan, konsep visualisasi dalam bentuk sketsa, hingga digitalisasi menggunakan perangkat keras dan lunak.

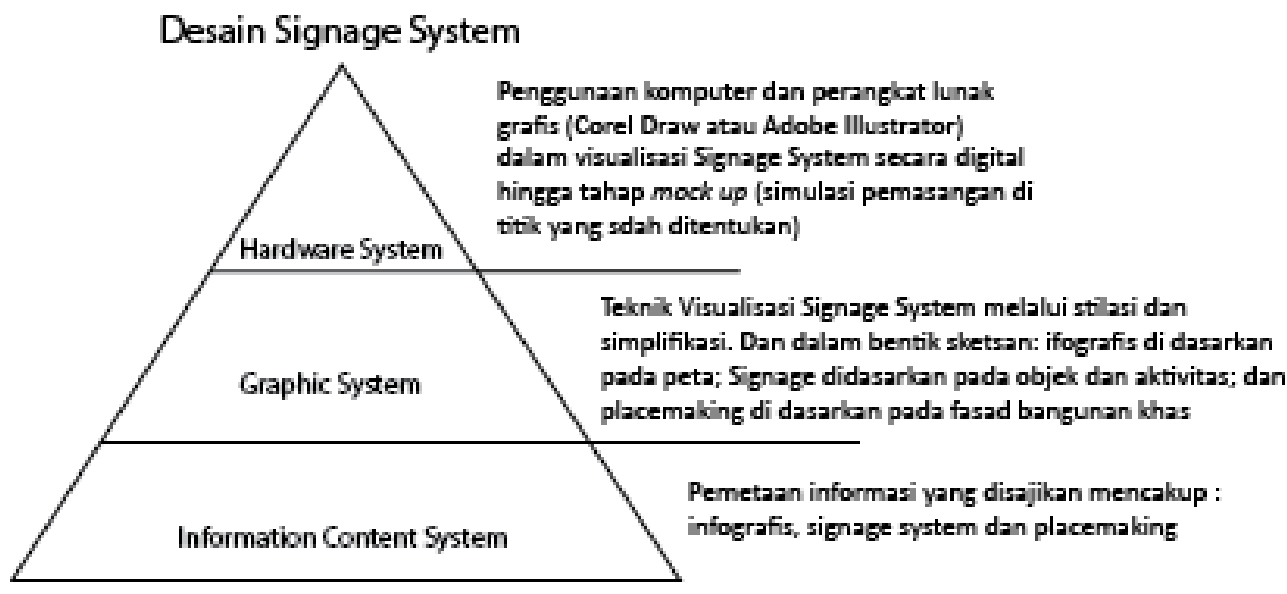

Gambar 6. Penerapan Signage Pyramid Method

[Sumber: Hananto \& et al., 2019:182]

Design Thinking diperlukan untuk menyusun konsep signage system yang akan dikerjakan sesuai dengan kriteria yang sudah ditentukan sebelumnya. Pada tahap Empathize, permasalahan utama terletak adanya signage system yang tidak konsisten beberapa ada yang terhalang pohon dan juga penempatan yang tidak sesuai. Pada tahap Define, statement pokok yang di dapat adalah menyajikan desain signage system berbasis komputer grafis yang komunikatif dan estetis agar media informasi bisa dihadirkan secara konsisten dan mencitrakan Simpang Lima sebagai kawasan modern dan kekinian. Pada tahapan Ideate, salah satu alternatif yang ditawarkan yaitu, merancang signage system di kawasan simpang lima dalam bentuk mockup, secara lebih detail untuk mengeksplorasi gaya desain, warna, pemilihan huruf, border, dan peletakan signage system sehingga nantinya audiens/khalayak dapat terbantu dengan adanya desain signage system yang dihasilkan. Dan terakhir pada tahap prototype gambar mockup dirancang oleh penulis menggambarkan penempatan dan peletakan signage system di kawasan simpang lima, apakah nantinya diletakan mounted on the wall atau menggunakan tiang (model flag). Secara umum, mockup nantinya digambar dengan 
pendekatan teknik stilasi dan simplifikasi untuk menghasilkan signage system yang mudah dipahami oleh khalayak. Setelah prototype berhasil dirancang tahap selanjutnya adalah test. mockup yang telah dirancang sesuai dengan konsep perlu diujikan kepada khalayak, yaitu para pengunjung kawasan simpang lima, sehingga bahan masukan dari khalayak dapat digunakan untuk menyempurnakan bentuk signage system sesuai dengan tujuan ini dicapai yaitu menyajikan desain signage system berbasis komputer grafis yang komunikatif dan estetis agar media informasi bisa dihadirkan secara konsisten dan mencitrakan Simpang Lima sebagai kawasan modern dan kekinian.

\subsubsection{Information Content System}

Pada tahap ini, penulis merumuskan tempat atau titik lokasi di kawasan Simpang Lima Semarang yang diprioritaskan untuk desain Signage System. Tidak semua lokasi di kawasan ini dibuatkan desain Signage System. Hanya beberapa lokasi yang dipilih sebagai perwakilan setiap jenis tempat yang berbeda satu sama lain.

Tabel 1. Pemetaan Information Content System dalam Signage System Kawasan Simpang Lima

[Sumber: Akrom dan Haryadi, 2020]

\begin{tabular}{|c|c|c|c|}
\hline No & Jenis Informasi & Penempatan & Kriteria \\
\hline 1. & Infografis & $\begin{array}{l}\text { Alun - alun, di dalam area } \\
\text { informasi Lapangan } \\
\text { Pancasila }\end{array}$ & $\begin{array}{l}\text { Peta Kawasan Simpang Lima dan } \\
\text { pemetaan tempat-tempat stretegis }\end{array}$ \\
\hline \multirow[t]{6}{*}{2.} & \multirow[t]{6}{*}{$\begin{array}{l}\text { Signage (dan } \\
\text { wayfinding) }\end{array}$} & Area Taman Indonesia Kaya & $\begin{array}{l}\text { Signage: parkir becak, dilarang } \\
\text { merusak tanaman, tempat sampah } \\
\text { non-daur ulang, dilarang memanjat, } \\
\text { dilarang menginjak rumput, air } \\
\text { minum } \\
\text { Wayfinding: area hijau, toilet }\end{array}$ \\
\hline & & Food Court & $\begin{array}{l}\text { Signage: dilarang parkir di area } \\
\text { pedestrian } \\
\text { Wayfinding: parkir mobil dan motor }\end{array}$ \\
\hline & & Masjid Baiturrahman & $\begin{array}{l}\text { Signage: dilarang berdagang } \\
\text { Wayfinding : parkir mobil dan motor }\end{array}$ \\
\hline & & $\begin{array}{l}\text { Gedung parkir Pandanaran } \\
\text { (pusat oleh-oleh) }\end{array}$ & Signage: ada kegiatan proyek \\
\hline & & Rumah sakit Telogo Rejo & $\begin{array}{l}\text { Signage: dilarang parkir } \\
\text { Wayfinding: Emergency Telogorejo }\end{array}$ \\
\hline & & Lapangan Pancasila & $\begin{array}{l}\text { Signage: lapangan voli, lapangan } \\
\text { basket, plosotan anak }\end{array}$ \\
\hline 3. & Placemaking & $\begin{array}{l}\text { Depan gedung: } \\
\text { - Masjid Baiturrahman } \\
\text { - Pemerintahan Provinsi } \\
\text { Jawa Tengah } \\
\text { - Bank Indonesia } \\
\text { - Semarang } \\
\text { - Telkomsel Semarang } \\
\text { - } \text { Tatahari Plaza } \\
\text { - Taman Indonesia Kaya }\end{array}$ & $\begin{array}{l}\text { Ikon fasad beberapa gedung di } \\
\text { kawasan Simpang Lima Semarang }\end{array}$ \\
\hline
\end{tabular}




\subsubsection{Graphic System}

Tahap desain signage system berikutnya yaitu memvisualisasikan konsep signage dan placemaking melalui sketsa manual dengan teknik stilasi dan simplifikasi, yakni menggayakan bentuk bangunan, objek, atau aktivitas dengan penyederhanaan bentuk sehingga bisa dikenali bentuknya dan mampu menyampaikan informasi. Bangunan, objek, dan aktivitas yang di visualkan dalam sketsa dibuat secara keseluruhan terlebih dahulu untuk memudahkan penggalian ide. Kemudian penulis melakukan eliminasi dan pemilahan gambar mana saja yang akan digunakan dan dilanjutkan tahap digitalisasi.
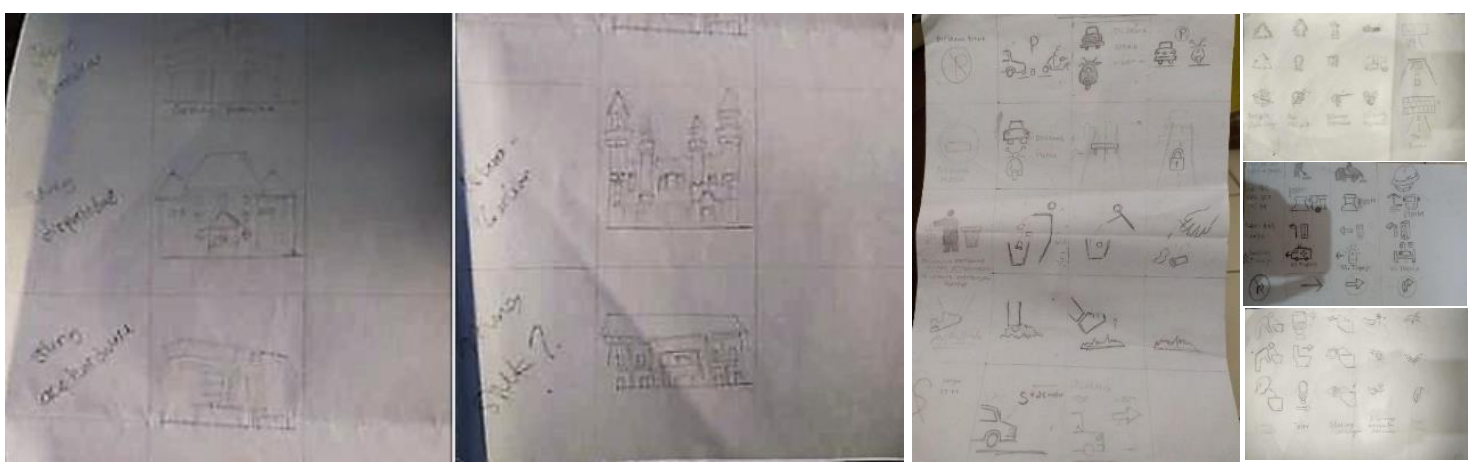

Gambar 7. Sketsa placemaking dan signage

[Sumber: Dokumentasi penulis]

\subsubsection{Hardware System}

Tahap ini merupakan digitalisasi sketsa desain signage system dengan teknik komputer grafis menggunakan perangkat keras notebook dan perangkat lunak pengolah grafis Corel Draw. Digitalisasi tetap mempertahankan stilasi dan simplifikasi dengan model siluet sehingga tidak banyak elemen desain dan fokus menggambarkan bangunan, aktifitas, atau objek sesuai dengan sketsa yang ada. Selain itu, pada tahap ini penulis melakukan eliminasi dan pemilahan desain signage system yang akan dibuat mock up sesuai dengan titik - titik lokasi yang telah dicantumkan dalam information content system.

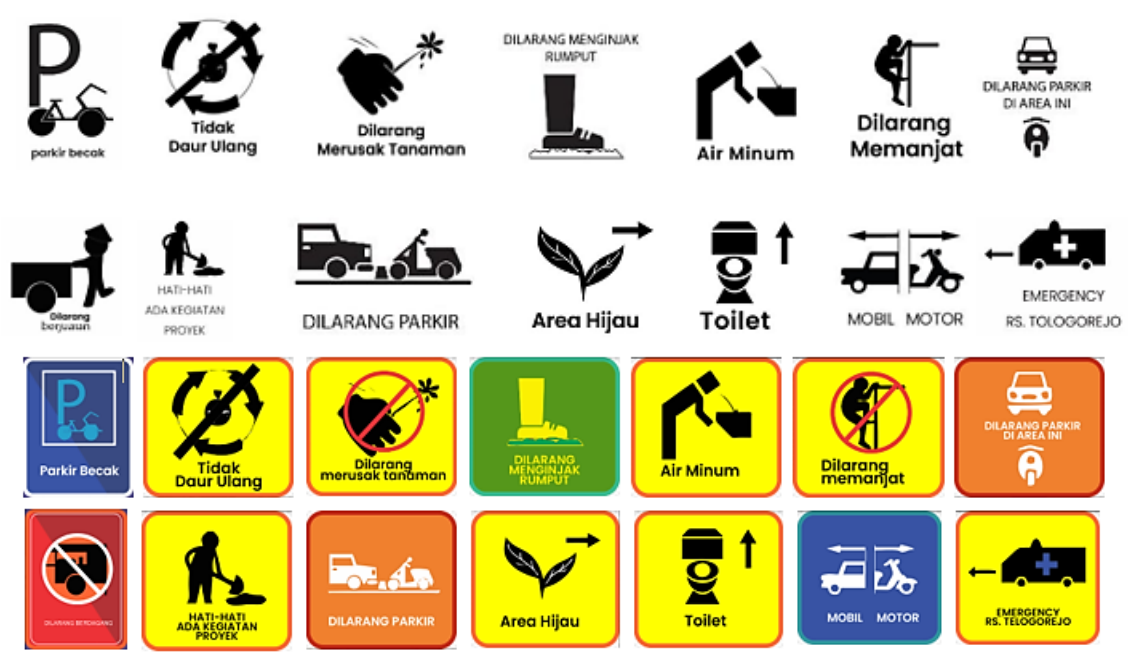

Gambar 8. Digitalisasi dan desain EGD Signage

[Sumber: Dokumentasi penulis] 

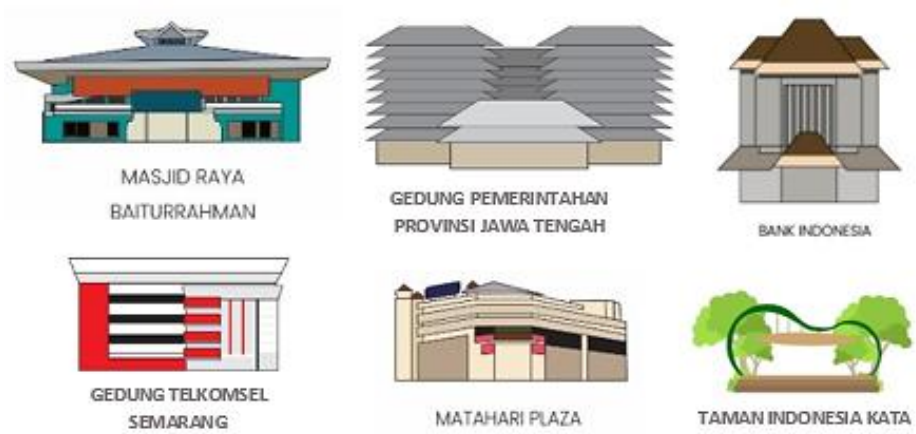

Gambar 9. Digitalisasi placemaking

[Sumber: Dokumentasi penulis]

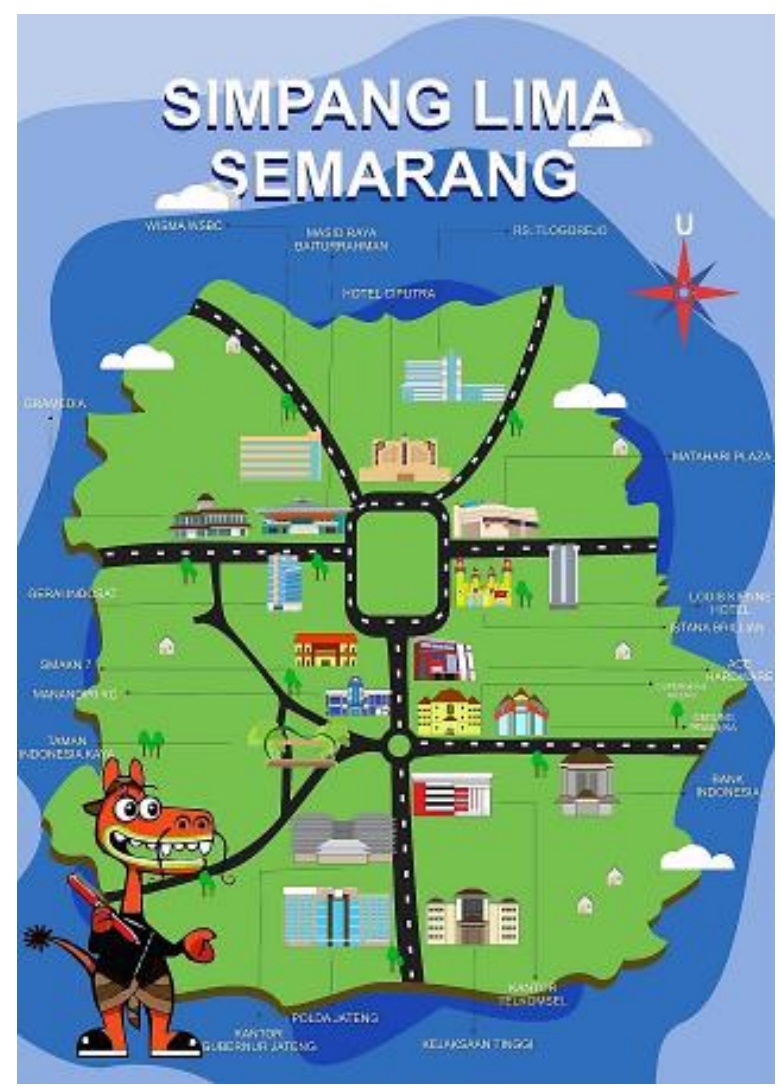

Gambar 10. Infografis kawasan Simpang Lima [Sumber: Dokumentasi penulis]

\subsection{Mock Up Signage System}

Ketiga tahap dalam signage pyramid method telah diimplementasikan dalam penelitian ini. Bagian terakhir yaitu konsep penempatan infografis, signage, dan placemaking pada beberapa titik yang mewakili tempat-tempat strategis di kawasan Simpang Lima Semarang. 
Tabel 2. Implementasi signage system dalam bentuk desain mock up [Sumber: Dokumentasi penulis]

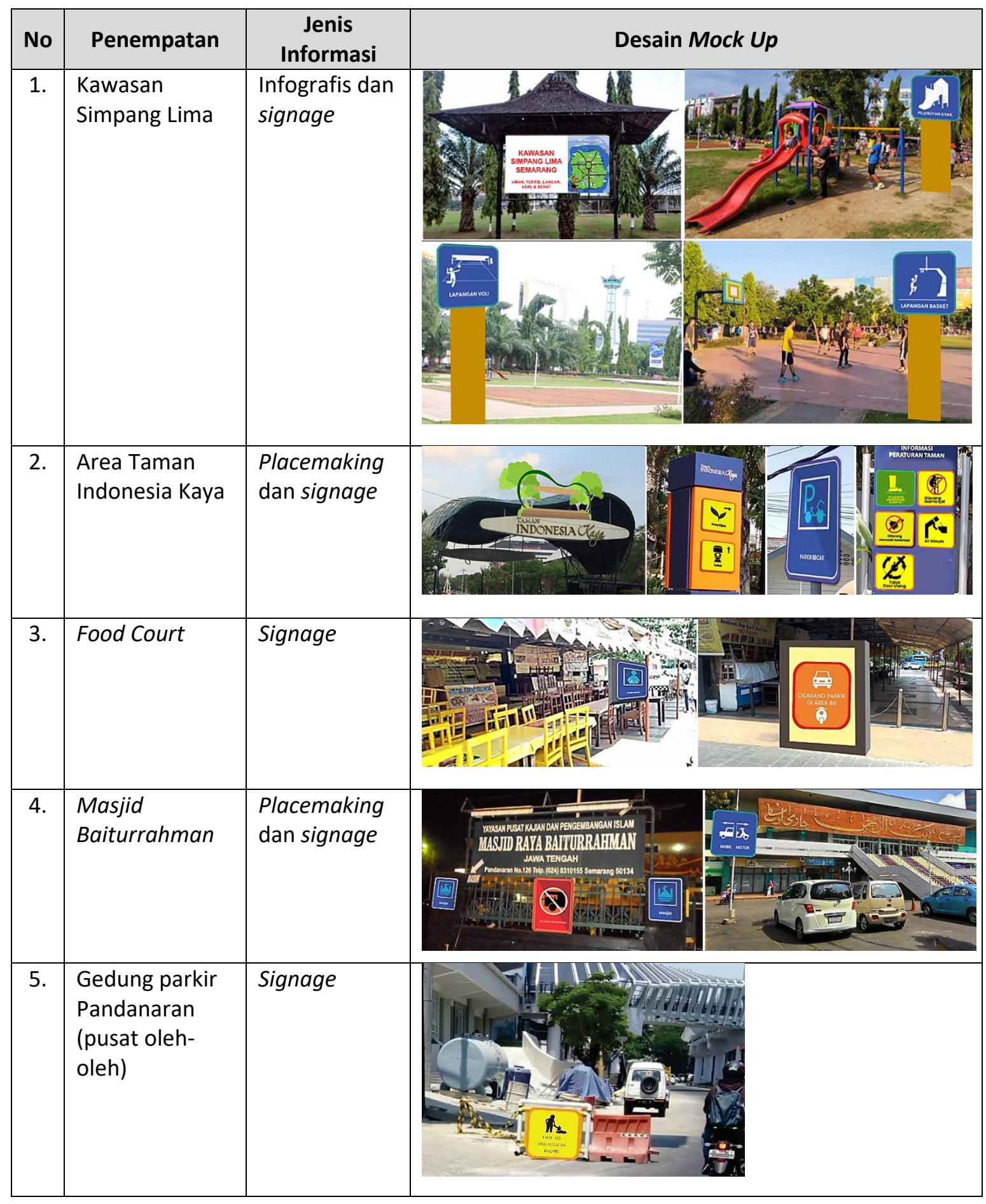




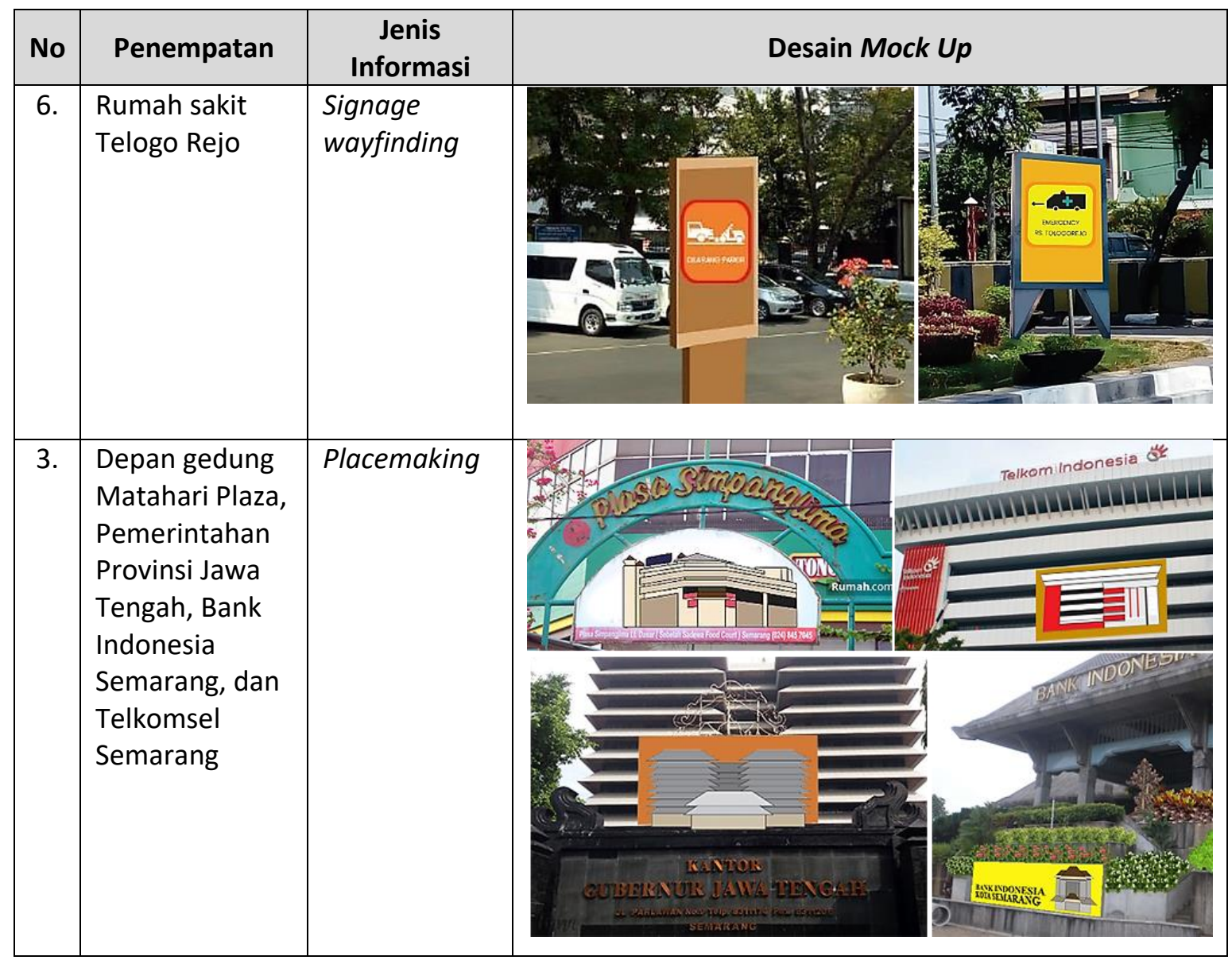

\section{KESIMPULAN}

Keberadaan desain signage system di kawasan Simpang Lima Semarang sangat diperlukan. Hal ini tidak terlepas dari posisi Simpang Lima sebagai kawasan strategis dan modern yang menjadi pusat berbagai kegiatan mulai dari refreshing, berbelanja, bekerja, dan pertunjukan. Melalui desain signage system ini, diharapkan pengunjung lokal maupun wisatawan dari luar Semarang bisa mengeksplorasi titik - titik strategis sehingga bisa menjaga potensi Simpang Lima. Berdasarkan pertimbangan penulis, tidak semua titik lokasi di Simpang Lima dibuat desain signage system. Hanya tempat-tempat tertentu yang dibuatkan desain signage system dengan pertimbangan bahwa tempat tersebut sering dikunjungi dan menjadi persinggahan pengunjung untuk mendukung kegiatan ibadah, rekreasi, belanja, serta tempat menukar uang dan gerai telekomunikasi. Sehingga penelitian ini bisa dikembangkan lebih jauh khususnya penyediaan media informasi signage system secara virtual dengan mengadaptasi teknologi Augmented Reality, yang bisa diakses melalui smartphone dengan mudah dan cepat. 


\section{DAFTAR PUSTAKA}

Aditya, N. R. 2020. Semarang, Kota Wisata Terbersih di ASEAN. (Updated 21 Januari 2020) URL: https://travel.kompas.com/read/2020/01/21/121500727/semarang-kotawisata-terbersih-di-asean?page=all [diakses pada 19 Desember 2020]

Amrullah, F. R., dan Tohir, M. 2017. Perancangan Sign System Objek Pariwisata Bersejarah Lawang Sewu di Kota Semarang. E-Proceeding of Art and Design, 4 (3), pp. 824-829.

Anggito, A. dan Setiawan, J. 2018. Metodologi Penelitian Kualitatif. Kabupaten Sukabumi: Jejak

Calori, C. dan Vanden-Eynden, D. 2015. Signage and Wayfinding Design: A Complete Guide to Creating Environmental Graphic Design Systems. New Jersey: Wiley \& Sons, Inc.

Hananto, B. A., et al. 2019. Kajian Desain Environmental Graphic Design Umeda Hospital. Gestalt, 1 (2), pp.177-190.

Haryadi, T. dan Saputro, G. E. 2018. Tinjauan Desain Iklan Dalam Sudut Pandang Majas Visual (Studi Kasus: Iklan Media Billboard di Kota Semarang). Demandia, 3 (1), pp. 97-115.

Kementerian Pekerjaan Umum dan perumahan Rakyat. 2010. Peraturan Menteri Pekerja Umum Nomor: 20/PRT/M/2010 (Tentang Pemanfaatan dan Penggunaan Bagian - Bagian Jalan). Jakarta

Kurniawan, Haris. 2020. Kota Semarang Raih Penghargaan Inovasi Tatanan Normal Baru dari Kemendagri. (Updated 22 Juni 2020) URL: https://www.merdeka.com/peristiwa/kota-semarang-raih-penghargaaninovasi-tatanan-normal-baru-dari-kemendagri.html [diakses pada 19 Desember 2020]

Maarif, Nurcholis. 2019. Kota Semarang Boyong 9 Penghargaan Kota Cerdas Indonesia dari ITB. (Updated 18 November 2019) URL: https://news.detik.com/berita/d4789519/kota-semarang-boyong-9-penghargaan-kota-cerdas-indonesia-dariitb [diakses pada 19 Desember 2020]

Nasrulhak, Akfa. 2019. Kota Semarang Raih 3 Penghargaan, Walkot Hendi: Mari Kita Pertahankan. (Updated 24 Juli 2019) URL: https://news.detik.com/berita/d4637634/kota-semarang-raih-3-penghargaan-walkot-hendi-mari-kitapertahankan [diakses pada 19 Desember 2020]

Prastomo, A. D. dan Widjaja, R. R. 2019. Facade Media Sebagai Alternatif Titik Reklame Pembentuk Visual Kota Semarang. Praxis, 1 (2), pp.196-210.

Ramdhan, H. E. 2016. Startupreneur: Menjadi Entrepreneur Startup. Jakarta: Penebar Plus

Santoso, R. E., Sari, S. R., dan Rukayah, R. S. 2020. Sirkulasi Manusia dan Kendaraan Pada Pedestrian Terhadap Koneksitas Simpang Lima Semarang. Arcade, 4 (1), pp.3540.

Widyaningrum, D., Sudarsono, B., dan Nugraha, A. L. 2017. Analisis Sebaran Reklame Billboard Terhadap Lokasi dan Nilai Pajak Reklame Berbasis Sistem Informasi Geografis. Geodesi, 6 (1), pp.100-109. 